\title{
ELECTROCHEMICAL DEGRADATION OF ALIZARIN BLACK DYE IN AQUEOUS MEDIUM USING FE/AL ELECTRODE
}

\author{
Haydar A. Mohammad Salim*, Shinwar Ahmed Idrees, Sabir Ayob Mohammed Salih, Reving Abdulazeez Rashid \\ Department of Chemistry, Faculty of Science, University of Zakho, Kurdistan Region - Iraq (hayder.Salim@uoz.edu.krd)
}

Received: May, 2019 / Accepted: Jun., 2019 / Published: Jun.,2019

$\underline{\text { https://doi.org/10.25271/siuoz.2019.7.2.601 }}$

\begin{abstract}
:
This work investigates the electro-catalytic degradation of alizarin black dye in an electrochemical cell using $\mathrm{Fe}$ as anode and $\mathrm{Al}$ as cathode. The influence of initial dye concentration, effect of salt, $\mathrm{pH}$, change of temperature and effect of change of applied voltage have been studied in addition, the influence of semiconductor dose has studied as well. In the current work roughly total removal of $70 \mathrm{mg} / \mathrm{L}$ of dye occurred in $16 \mathrm{~min}$ only. The results showed that effect of both electrolyte concentration and applied voltage was positive if combined together and the rate of degradation in neutral medium was the best for degradation of Alizarin black dye.
\end{abstract}

KEYWORDS: Electro Catalytic Oxidation, Alizarin Black Dye, Semiconductors.

\section{INTRODUCTION}

Water contamination denote to the presence of a harmful and destructive material in water, even at very low concentrations, which makes it unsuitable for drinking purpose. Water pollution debilitates or obliterates natural ecosystems that help human health, nourishment generation and biodiversity. The issue is particularly looked by developing nations, because of quick increment in industries (Kaur \& Kaur, 2016). In textile industries, huge quantity -of dyes are lost to the effluents throughout manufacturing and processing operations. These effluents, due to the existence of metals and other chemicals in their structure, are either toxic or cancer-causing. Therefore, many new treatments are needed for either removal of dyes or converting them to harmless compounds in water body (S. A. M. S. Haydar A. Mohammad Salim, Reving A. Rashid, 2016; Mohammad Salim \& Simo, 2015; Haydar A Mohammad Salim \& Salih, 2015; Haydar A Mohammad Salim, Salih, \& Simo, 2014; Hayda A Mohammad Salim, Simo, \& Yaseen, 2014; H. M. Salim, 2015; Tizaoui, Mohammad-Salim, \& Suhartono, 2015).

Powerful and economic treatments of dyes effluent have progressed toward becoming a genuine worry in the course of recent decades. No single conventional treatment system is satisfactory for breaking down the dye structure. At present, much research has focused on chemical and physical degradation of dyes in wastewater body (S. M. S. Haydar A. Mohammad Salim, 2015; Mohammad Salim, 2017; Haydar A Mohammad Salim et al., 2014; Soloman et al., 2009). These methods include advanced oxidation techniques which use strong oxidizers such as hydrogen peroxide (Meriç, Kaptan, \& Ölmez, 2004), ozone (Franco, Jardim, Boodts, \& Da Silva, 2008), semiconductors (Shinwar Ahmed Idrees \& Ibrahim, 2018; Haydar A Mohammad Salim et al., 2018) etc. Electrochemical removal of dyes effluent on noble metal oxide removes the generation of chemical sludge and is thus important regarding process costs and simplicity of the process. Trying complete mineralization of large volumes of such a heavy loaded organic effluent is questionable. However, the possibility of coupling of electro-chemical methods with conventional methods for an enhancement, economically viable overall performance may be inspected (Soloman et al., 2009). In electro-chemical process, the primary reagent is the electron, called the "Clean Reagent," which breaks down all the organics present in the effluent without creating any side contamination or by-product. The electro-chemical method offers high degradation efficiencies even at lower temperature if compared to non-electrochemical treatment (Morsi, AlSarawy, \& El-Dein, 2011). The aim of this work was to describe the electrochemical oxidation of alizarin black in sodium chloride solution using aluminum/iron electrodes as cathode and anode in turn semiconductor has been examined as well.

\section{EXPERIMENTAL PART}

\subsection{Method}

The electro chemical degradation experiments were performed under galvanostatic condition and the voltage was drawn from a DC power supply (victor stabilized power supply $1.5-15 \mathrm{v} / 5 \mathrm{~A}$, MOD.V-5016R) as in figure 1, the electrolysis of dye solution was carried out at different temperature, salt concentration, voltage and semiconductor dose. The volume of cell was $250 \mathrm{~mL}$ and all experiment was performed at constant stirring using magnetic stirrer.

To follow the degradation process, small portion of sample analyze were taken out at regular time intervals; UV-Visible absorbance spectrum was recorded using (UV.-vis. Spectrophotometer type Perkin-Elmer lambda 25) as shown in figure (2 and 3 ).

The percentage of alizarin black dye degradation with referring to the absorption spectra at $\lambda \max$ was calculated using the equation:

$$
\% \mathrm{R}=\left[\left(\mathrm{A}_{\mathrm{o}}-\mathrm{A}_{\mathrm{t}}\right) / \mathrm{A}_{\mathrm{o}}\right]^{*} 100
$$

Where $\% \mathrm{R}$ is the removal percent, $\mathrm{A} 0$ and At are the absorbance at maximum absorbance, at time 0 and $t$ minutes of Electro chemical processes, respectively (Rao \& Venkatarangaiah, 2014). 


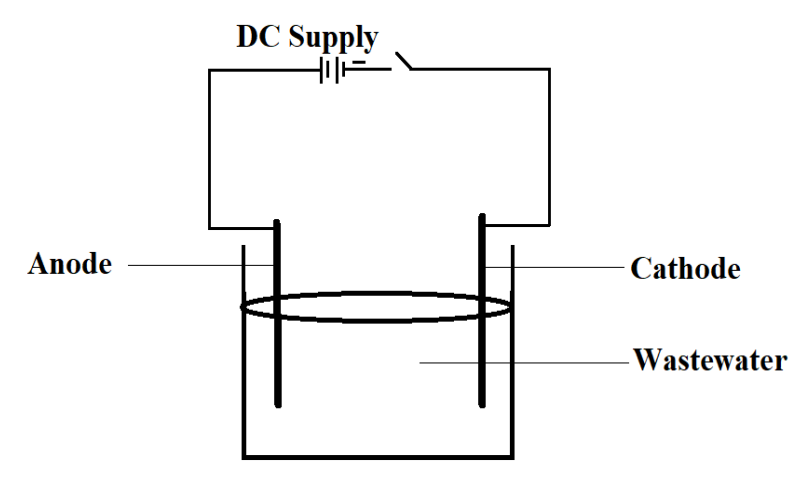

Figure 1. Schematic illustration of electro-catalytic degradation.

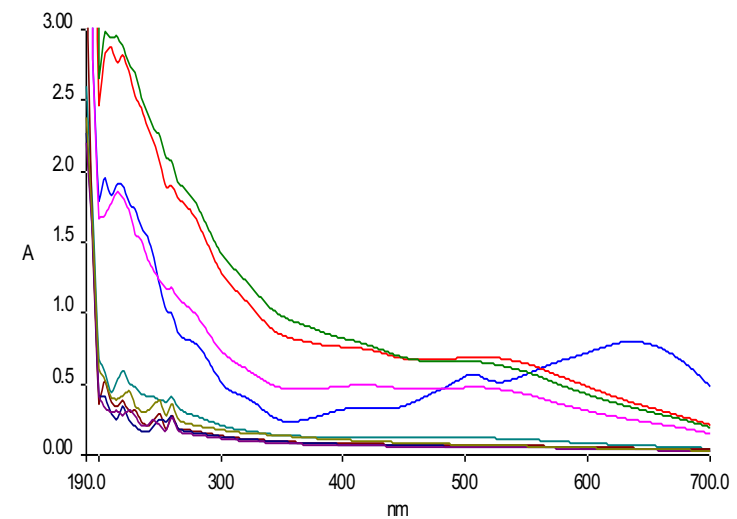

Figure 2. UV.-Vis. Spectral change for the degradation of $70 \mathrm{ppm}$ of alizarin black, $0.2 \mathrm{~g} / \mathrm{L} \mathrm{NaCl}, 15 \mathrm{ev}$ ROOM TEMP.

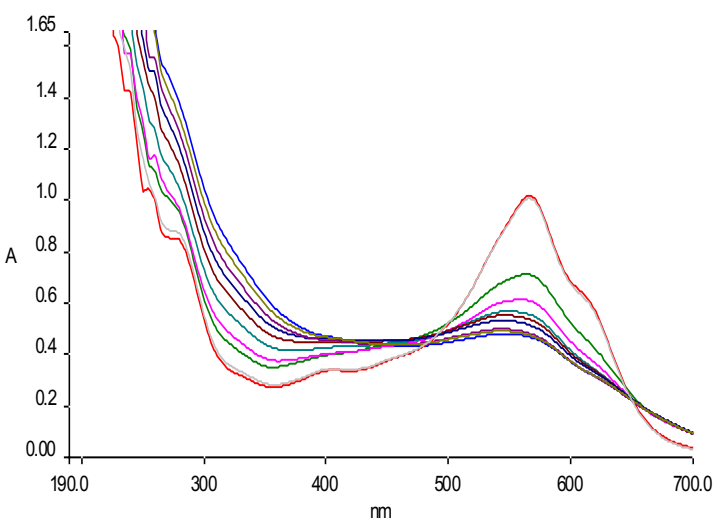

Figure 3. UV.-vis. Spectral change for the degradation of alizarin black $15 \mathrm{ev}, 0.02 \mathrm{~A}, \quad 0.4 \mathrm{~g} / \mathrm{L} \mathrm{ZnO}$ ROOM TEMP.

The color line in both figure 2 and 3 represents the degradation process of alizarin dye after passing two minutes in case of figure 2 and three minutes with regards to figure 3 starting from zero time of degradation until 16 minutes in figure two and 24 minutes in case of figure 3 .

\subsection{Material}

Acid Alizarin Black (AAB) was purchased from Hopkin and Williams LTD, UK and used as received. A stock solution of AAB $(1,000 \mathrm{mg} / \mathrm{L})$ was prepared on a daily basis in distilled water and other concentrations $(30 \mathrm{mg} / \mathrm{L}, 50 \mathrm{mg} / \mathrm{L}$ and $70 \mathrm{mg} / \mathrm{L})$ were prepared by dilution the stock solution of $\mathrm{AAB}$ prepared stock solution was covered by aluminum foil and kept in dark. . The Zinc oxide $(\mathrm{ZnO})$ was purchased from Alpha Chemika, India. Sodium chloride was purchased from Fisher-Scientific, UK.

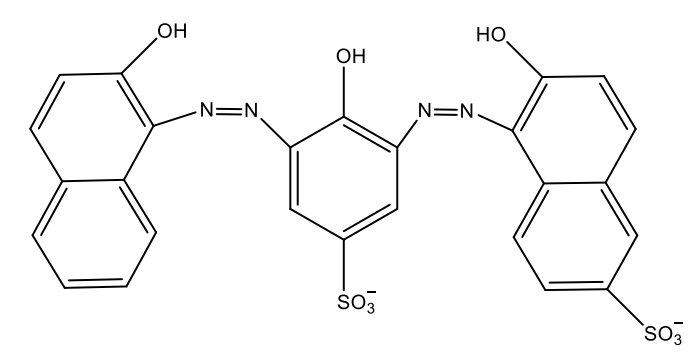

\section{RESULT AND DISCUSSION}

\subsection{Effect of initial dye concentration}

The influence of the initial concentration of alizarin black dye on its electro-catalytic removal rate was studied using $(40,50$, 60 and $70 \mathrm{mg} / \mathrm{L}$ ) with $0.1 \mathrm{M} \mathrm{NaCl} 15 \mathrm{v}$ and at neutral $\mathrm{pH}$ value. Figure 4 shows the percentage of degradation of initial dye concentration with respect to time. The results illustrate that the degradation of $50 \mathrm{ppm}$ is faster than other concentrations. However, there is randomness among degradation percentage this perhaps due to the formation of different compound during electro-degradation process as shown in fig. 2 which interferes with degradation paths. Regarding high concentration there is a decrease in removal percentage this this is because of the increasing number of intermediates produced at higher dye concentrations which compete electro-oxidation of alizarin black at the electrode surface (Emran, Ali, \& Al-Oufi, 2018). Hence, adversely influence on day removal percentage. With regards to this difference in percentage was not of that importance $100,99.4,98.9$ and $98.6 \%$ for $40,50,60$ and $70 \mathrm{ppm}$ respectively.

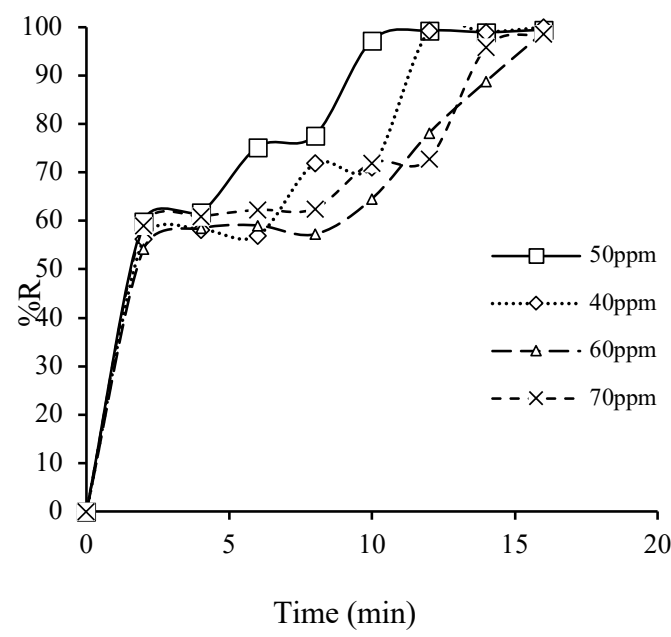

Figure 4. Effect of initial dye conc. $($ applied voltage $=15 \mathrm{ev}$, Vol.e $=250$ $\mathrm{mL},[\mathrm{NaCl}]=0.1 \mathrm{~g} / \mathrm{L}, \mathrm{pH}=6.7)$

\subsection{Effect of salt added}

The influence of electrolyte concentration was studied and for this purpose sodium chloride was used with various concentration $(0.1,0.15$ and $0.2 \mathrm{~g} / \mathrm{L})$. The result shows that at a given $\mathrm{NaCl}$ concentration throughout the experiment the removal percentage of alizarin black dye were generally increased with the increasing the salt concentration, as shown in figure (5). This may be due to the increasing of formation of hypochlorite ion (OCl-) at anode and electrical conductivity as well (Sh A Idrees, Naman, \& Shorachi, 2018). 


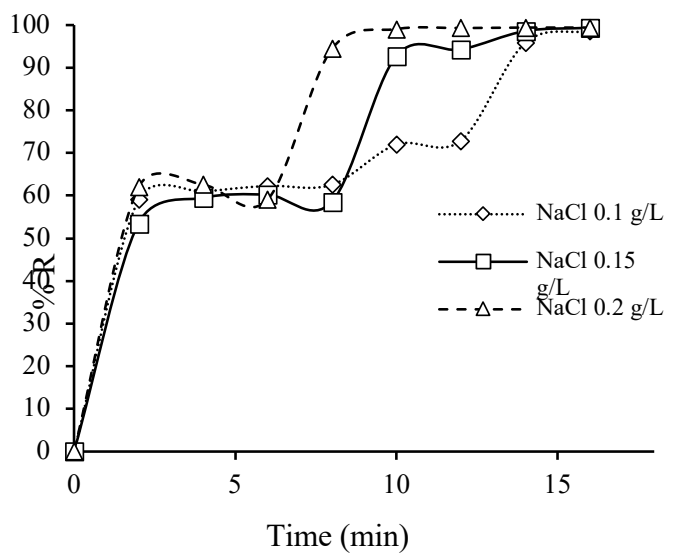

Figure 5. Effect of salt conc. (applied voltage $=15 \mathrm{ev}$, Vol.e $=250 \mathrm{~mL}$, [dye] $70 \mathrm{mg} / \mathrm{L}, \mathrm{pH}=6.7$ )

\subsection{Effect of $\mathrm{pH}$ of solution}

The influence of $\mathrm{pH}$ of solution on electro-catalytic degradation has been examined applying $(\mathrm{pH}=3,6.7$ and 10$)$ at constant applied voltage, temperature and electrolyte dose. The best result was in case of neutral solution $98.6 \%$ was degraded after 16 minute of degradation time. On the other hand, basic solution was not working well if compared to neutral and acidic solution with 79.6 and $55.4 \%$ for acidic and basic solution respectively in a given degradation time. As shown in figure 6.

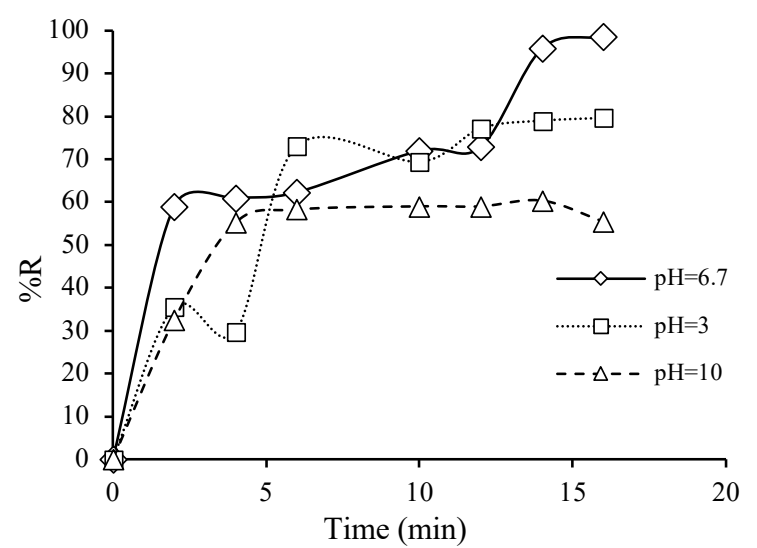

Figure 6. Effect of $\mathrm{pH}$ (applied voltage $=15 \mathrm{v}$, Vol.e $=250 \mathrm{~mL},[\mathrm{NaCl}]$ $=0.1 \mathrm{~g} / \mathrm{L},[$ dye $]=70 \mathrm{mg} / \mathrm{L}$ )

\subsection{Effect of temperature}

This investigation has been carried out in $0.1 \mathrm{~g} / \mathrm{L}$ sodium chloride solution and at operating condition: applied voltage $15 \mathrm{ev}, 70 \mathrm{mg} / \mathrm{L}$ initial alizarin black concentration and contact time was 16 minute per run at each temperature. It was shown that with increasing temperature the rate of the percentage of dye removal increases at a given condition, as shown in figure (7).

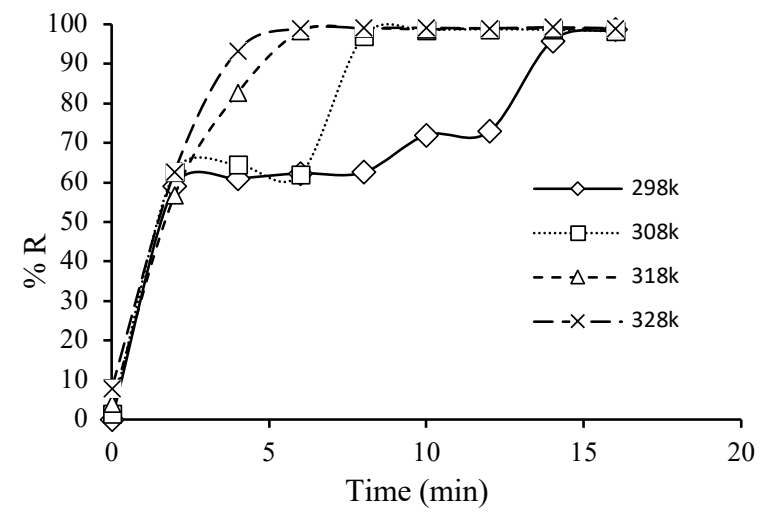

Figure 7. Effect of temperature (applied voltage $=15 \mathrm{ev}$, Vol.e $=250$ $\mathrm{mL},[\mathrm{NaCl}]=0.1 \mathrm{~g} / \mathrm{L}, \mathrm{pH}=6.7,[$ dye $]=70 \mathrm{mg} / \mathrm{L}$ )

\subsection{Effect of applied voltage}

Various voltage densities value $(5,10$ and $15 \mathrm{v})$ were applied to solution that contain constant amount of operating condition including: $0.1 \mathrm{~g} / \mathrm{L}$ electrolyte concentration, $\mathrm{pH}$ of solution was 6.7 , temperature $298 \mathrm{~K}$ and initial dye concentration was 70 $\mathrm{mg} / \mathrm{L}$. The results show that at a given applied voltage the percentage of dye removal increases as a function of contact time until reached the limiting value. As the applied voltage increases the dye removal percentage increases about 60.3, 82.85 and $98.6 \%$ for applied voltage 5,10 and $15 \mathrm{ev}$ in turn at a given degradation time which was 16 minute per run, as shown in figure (8).

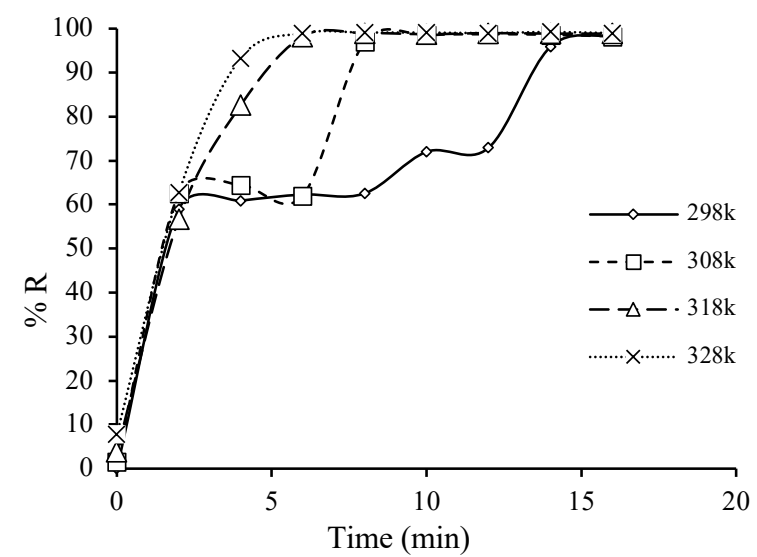

Figure 8. Effect of applied voltage $($ Vol.e $=250 \mathrm{~mL},[\mathrm{NaCl}]=0.1 \mathrm{~g} / \mathrm{L}$, $\mathrm{pH}=6.7,[$ dye $]=70 \mathrm{mg} / \mathrm{L}$ )

\subsection{Effect of semiconductor dose}

The influence of $\mathrm{ZnO}$ was studied at different voltage intensity (5, 10 and $15 \mathrm{ev})$ and other operating condition were kept constant throughout the experiments $(0.4 \mathrm{~g} / \mathrm{L} \mathrm{ZnO}$ dose, $\mathrm{pH}=$ 6.7 , [dye $]=70 \mathrm{mg} / \mathrm{L}$ and all experiments were carried out at ambient temperature $25^{\circ} \mathrm{C}$ ). The aim of this part of research was to investigate the effect of applied voltage on the semiconductor efficiency. The results investigate that the increase of applied voltage does not have a remake able influence on the percentage of dye removal $53.9,54.1$ and $50.55 \%$ for 15,10 and $5 \mathrm{ev}$ respectively, as shown in figure (9). This due to the fact that gap energy (band gap) of Zinc oxide is roughly $3.2 \mathrm{ev}$ that means for the valence bond to be exited to the conduction band more than $3.2 \mathrm{v}$ is needed, as a result higher voltage dose not influence on $\mathrm{ZnO}$ work $[12,13]$.

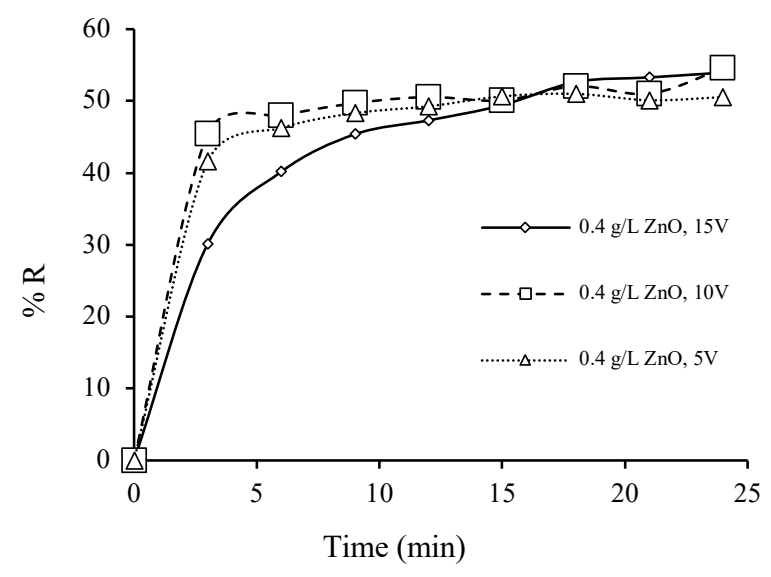

Figure 9. Effect of semiconductor (temperature $=298 \mathrm{~K}$, Vol.e $=250$ $\mathrm{mL},[\mathrm{NaCl}]=0.1 \mathrm{~g} / \mathrm{L}, \mathrm{pH}=6.7,[$ dye $]=70 \mathrm{mg} / \mathrm{L}$ )

\subsection{Kinetic study}

The kinetic study was difficult to be measured because new compound was formed during degradation process with different wave length, as shown in fig (2). On the other hand, after examining the order of degradation using integration laws 
of kinetics the degradation by $\mathrm{ZnO}$ was shown first order, as shown in fig (3 and10).

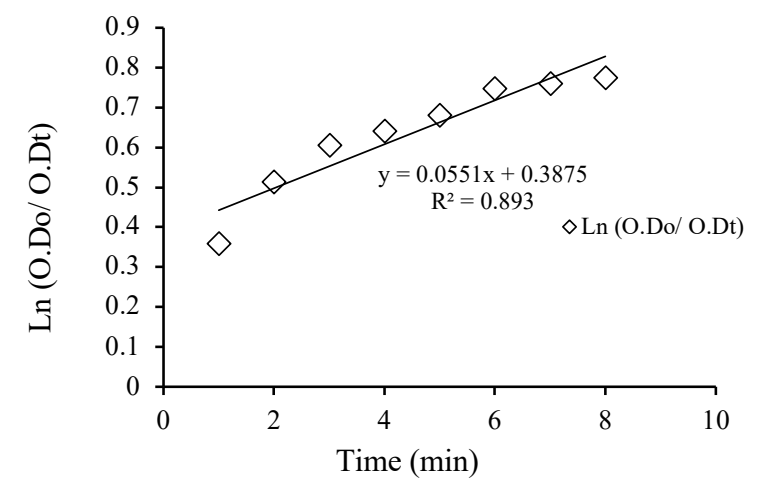

Figure 10. First order kinetics of electro-catalytic removal of alizarin black dye using semiconductor $(\mathrm{ZnO}=0.4 \mathrm{mg} / \mathrm{L}, \mathrm{Vol} .=250 \mathrm{~mL}, \mathrm{pH}=$ 6.7 , temperature $=298 \mathrm{k}$, applied voltage $=15 \mathrm{v}$ )

\section{CONCLUSION}

Electro-catalysis was successfully applied for the removal of alizarin blue dye if compared to similar research with different mechanism of degradation such as photo catalysis. The result has been obtained from this research was given a better results than that of photodegradation. A research was done by Salim [2] showed that for nearly total mineralization process for $30 \mathrm{mg} / \mathrm{L}$ of dye, 50 minute was needed, however, in the current work roughly total removal of $70 \mathrm{mg} / \mathrm{L}$ of dye was 16 minute only. Effect of different parameter was studied including temperature, semiconductor dose, initial dye concentration, $\mathrm{pH}$, electrolyte concentration and applied voltage. The results were shown that effect of both electrolyte concentration and applied voltage was positive if combined together and acidic medium was the best.

\section{REFERENCES}

Emran, K. M., Ali, S. M., \& Al-Oufi, A. L. (2018). The Electrocatalytic Activity of Polyaniline/TiO2 Nanocomposite for Congo Red Degradation in Aqueous Solutions. Int. J. Electrochem. Sci, 13, 5085-5095.

Franco, D. V., Jardim, W. F., Boodts, J. F., \& Da Silva, L. M. (2008). Electrochemical ozone production as an environmentally friendly technology for water treatment. CLEAN-Soil, Air, Water, 36(1), 34-44.

Haydar A. Mohammad Salim, S. A. M. S., Reving A. Rashid. (2016). Removal of Acid Alizarin Black Dye from Aqueous Solution by Adsorption Using Zinc Oxide. International Research Journal of Pure \& Applied Chemistry, 11(2), 1-8.

Haydar A. Mohammad Salim, S. M. S. (2015). HETEROGENEOUS PHOTODEGRADATION OF DYE USING TWO DIFFERENT TYPE OF LOCAL CLAYS AS A CATALYSTS. Paper presented at the ICEEE.

Idrees, S. A., \& Ibrahim, M. K. (2018). Optimization of Congo-Red Photo-Catalytic Degradation by Central Composite
Design. Paper presented at the 2018 International Conference on Advanced Science and Engineering (ICOASE).

Idrees, S. A., Naman, S., \& Shorachi, A. (2018). Kinetic and thermodynamic study of Trifluralin photo-degradation by ultra violet light. Paper presented at the IOP Conference Series: Materials Science and Engineering.

Kaur, R., \& Kaur, H. (2016). Electrochemical Degradation of Congo Red from Aqueous Solution: Role of Graphite Anode as Electrode Material. Portugaliae Electrochimica Acta, 34, 185-196. Retrieved from http://www.scielo.mec.pt/scielo.php?script=sci arttext\&pi $\mathrm{d}=\mathrm{S} 0872-19042016000300003 \& \mathrm{nrm}=$ iso

Meriç, S., Kaptan, D., \& Ölmez, T. (2004). Color and COD removal from wastewater containing Reactive Black 5 using Fenton's oxidation process. Chemosphere, 54(3), 435-441.

Mohammad Salim, H. A. (2017). FENTON DEGRADATION OF FAST GREEN DYE. Paper presented at the 2nd INTERNATIONAL SCIENTIFIC CONFERENCE UNIVERSITY OF ZAKHO.

Mohammad Salim, H. A., \& Simo, S. M. (2015). A comparison study of two different types of clay for heterogeneous photo degradation of dye. International Journal of Advanced and Applied Sciences, 2(2), 6-10.

Morsi, M., Al-Sarawy, A., \& El-Dein, W. S. (2011). Electrochemical degradation of some organic dyes by electrochemical oxidation on a $\mathrm{Pb} / \mathrm{PbO} 2$ electrode. Desalination and Water Treatment, 26(1-3), 301-308.

Rao, A. N., \& Venkatarangaiah, V. T. (2014). The Effect of Cathode Materials on Indirect Electrochemical Oxidation of Methyl Orange, Malachite Green and Methylene Blue. Portugaliae Electrochimica Acta, 32(3), 213-231.

Salim, H. A. M., Idrees, S. A., Rashid, R. A., Mohammed, A. A., Simo, S. M., \& Khalo, I. S. (2018). Photo-catalytic degradation of Toluidine Blue Dye in Aqueous Medium Under Fluorescent Light. Paper presented at the 2018 International Conference on Advanced Science and Engineering (ICOASE).

Salim, H. A. M., \& Salih, S. A. M. (2015). Photodegradation Study of Toluidine Blue Dye in Aqueous Solution using Magnesium Oxide as a Photocatalyst. International Journal of Chemistry, 7(2), 143.

Salim, H. A. M., Salih, S. A. M., \& Simo, S. M. (2014). Homogeneous Photocatalytic Degradation of Acid Alizarin Black Using Hydrogen Peroxide. Science Journal of University of Zakho, 2(2), 329-335.

Salim, H. A. M., Simo, S. M., \& Yaseen, N. A. (2014). Photocatalytic Degredation of Acid Alizarin Black Using Powder and Nanoparticles of Titanium Dioxide. Science Journal of University of Zakho, 2(2), 336-341.

Salim, H. M. (2015). Photodegradation of Alizarin Black S Dye Using Zinc Oxide. JOURNAL OF ENVIRONMENTAL ENGINEERING AND SCIENCE, 4(8), 395-400.

Soloman, P. A., Basha, C. A., Velan, M., Ramamurthi, V., Koteeswaran, K., \& Balasubramanian, N. (2009). Electrochemical degradation of Remazol Black B dye effluent. CLEAN-Soil, Air, Water, 37(11), 889-900.

Tizaoui, C., Mohammad-Salim, H., \& Suhartono, J. (2015). Multiwalled carbon nanotubes for heterogeneous nanocatalytic ozonation. Ozone: Science \& Engineering, $37(3), 269-278$. 